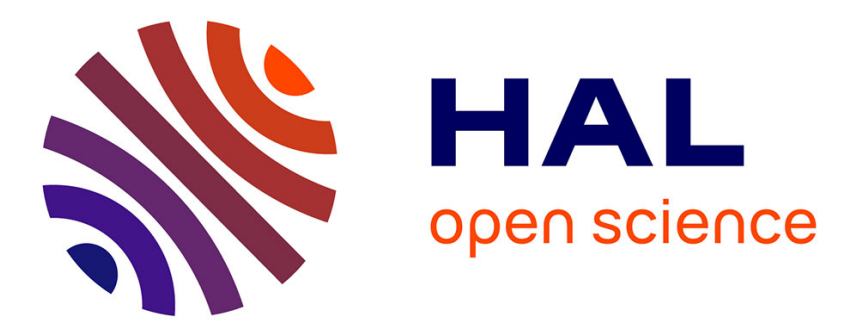

\title{
The efficiency of schools in developing countries, analysed through PISA 2012 data
}

Tommaso Agasisti, Pablo Zoido

\section{To cite this version:}

Tommaso Agasisti, Pablo Zoido. The efficiency of schools in developing countries, analysed through PISA 2012 data. Socio-Economic Planning Sciences, 2019, 68, pp.100711 10.1016/j.seps.2019.05.002 . hal-03488522

\section{HAL Id: hal-03488522 \\ https://hal.science/hal-03488522}

Submitted on 21 Dec 2021

HAL is a multi-disciplinary open access archive for the deposit and dissemination of scientific research documents, whether they are published or not. The documents may come from teaching and research institutions in France or abroad, or from public or private research centers.
L'archive ouverte pluridisciplinaire HAL, est destinée au dépôt et à la diffusion de documents scientifiques de niveau recherche, publiés ou non, émanant des établissements d'enseignement et de recherche français ou étrangers, des laboratoires publics ou privés.

\section{다(1) $\$$}

Distributed under a Creative Commons Attribution - NonCommerciall 4.0 International 


\title{
The efficiency of schools in developing countries, analysed through PISA 2012 data
}

\author{
Tommaso Agasisti ${ }^{* * *}$ \\ * Politecnico di Milano School of Management, \\ Department of Management, Economics and Industrial Engineering \\ e. tommaso.agasisti@polimi.it \\ ** TJ Alexander Fellow, OECD \\ Pablo Zoido ${ }^{+}$ \\ ${ }^{+}$Inter-American Development Bank
}

\begin{abstract}
This paper analyses the efficiency of more than 6,800 schools in 28 developing countries, by means of a two-stage Data Envelopment Analysis and using data from OECD PISA 2012. The results reveal that the average efficiency of schools is around $70 \%$, meaning that achievement scores can be raised by $30 \%$ by employing a more effective use of available resources. Substantial heterogeneity exists both between and within countries; in general, efficiency scores are higher when comparing schools only with those in the same country. Among factors associated with schools' efficiency, the most important are the characteristics of student population (for instance, motivation, truancy, etc.). Therefore, some practices related to accountability, teachers' involvement and professional development, and extracurricular activities are also positively associated with higher levels of efficiency.
\end{abstract}

\section{Keywords}

Schools' efficiency; Data Envelopment Analysis (DEA); developing countries; educational policies; OECD-PISA 2012

\section{JEL Codes}

$\mathrm{I} 21, \mathrm{I} 25, \mathrm{I} 28$

Acknowledgment and disclaimers

The present research is funded under the OECD Thomas J. Alexander fellowship (Tommaso obtained the Fellowship in the Fall of 2013). Tommaso is grateful to OECD EDU team who hosted him in Paris during the Summer 2014, when he realised the most part of empirical analyses reported here. He received useful comments by F. Avvisati and F. Borgonovi. The work should not be reported as representing the official views of the OECD or of its member countries. The opinions expressed and arguments employed herein are those of the authors. 


\section{Motivation, background and research questions}

Empirical evidence about the role of human capital (HC) in fostering economic growth and social prosperity (Hanushek \& Woessmann, 2008) has led to increasing attention on education in low-income and developing countries. The policy rationale is that improving HC stock would help, in the medium-long run, to increase these countries' capacity to grow rapidly and sustainably.

However, favouring more flows of money to education is not enough; it is also necessary to verify that resources are employed in effective and efficient ways - that is to say, each dollar is used to "produce" the highest possible level of students' achievement. In this educational process, the role of schools as organisations is crucial. Indeed, the transmission of knowledge - which is at the basis of achievement - does happen in an organised manner within schools. Following to this reasoning, a cultural movement during 1990s and 2000s promoted the socalled "School-Based Management" (SBM), which is thought to devolve managerial functions from the government to the schools (for a description of SBM and its effects, see Leithwood \& Menzies, 1998). This strategy has been promoted especially in developing countries, and the World Bank has been the main institution in implementing coherent policies in different settings and through various projects (Patrinos \& Fasih, 2009). Nevertheless, recent empirical research suggested that school autonomy is not effective for schools operating in developing countries, while it is beneficial for students in the more developed economies (Hanushek et al., 2013).

In analysing the correlation between spending in education and results obtained, previous contributions suggested that some countries are able to obtain, for each dollar spent, higher achievement levels than others (for analysis at country levels, see Clements, 2002; Afonso \& St. Aubyn, 2006; Agasisti, 2014a). Interestingly, the presence of differential levels of efficiency has also been detected in developing economies, as demonstrated by Gupta et al. (2002), albeit higher levels of spending are likely to be conducive to better results. In their conclusions, authors have argued that greater spending on educational systems seems actually associated with better academic results (as measured through attainment rates).

Analyses conducted at country level are only partially informative, thus; even though they help in understanding the differences in average performances, they neither indicate how these performances were generated (i.e. precise characteristics of the educational sector), nor how performances are distributed within the country, (i.e. between schools). For all these reasons, it appears useful to investigate the efficiency of education not at a country level, but instead at school level, in other words considering how different are results obtained by different schools.

One major innovation of this study is its focus on low-income and developing countries, as well as its international perspective. While efficiency studies have been performed since 1990s in many countries (especially developed western countries, such as US, Australia, UK, etc. ${ }^{1}$ ), the literature about the efficiency of schools in low-income and developing countries is still very limited particularly in recent years. For example, Bogetic \& Chattopadhyay (1995)

\footnotetext{
${ }^{1}$ Some early reviews or surveys of studies about schools' efficiency can be found in Worthington (2001) and Johnes (2004). A recent review that includes studies on developing countries can be found in De Witte \& Lopez-Torres (2017); while our paper considers only a subsample of existing studies about these countries, a wider list of them can be found in their work.
} 
calculated efficiency scores for Bulgarian high schools, and show that institutions in rural areas are less efficient than those in cities (with those in the main city, Sofia, being the most efficient). Lassibille \& Tan (2001) compared the efficiency scores of different school types in Tanzania, and reveal that public schools demonstrate better performance than private schools. Mizala et al. (2002) investigated the technical efficiency of primary schools in Chile, finding a high average efficiency level (93\%), with private schools performing more efficiently than their public counterparts. Essid et al. (2010) studied the efficiency of high schools in Tunisia, and demonstrated that schools with ancillary services (i.e. residential ones) should reduce their resources to be deemed efficient. Al-Enezi et al. (2010) and Burney et al. (2013), in two related papers, used Data Envelopment Analysis (DEA) for measuring the efficiency of schools in Kuwait for several educational levels, and discovered that teacher salaries are highly significant in explaining school efficiency at all levels.

Literature about international comparison of schools' efficiency is in its very infancy. It is probably one of the most interesting trends of research in the near future. Indeed, it would enable schools to observe different combinations of inputs and outputs, i.e. different activities, practices and processes beyond those that are typical in a given country. Enlarging the scope of analysis, i.e. comparing schools against a set of counterparts in several different countries, would help to enlarge the perspective of each school, helping the process of spurring innovation and new ideas of how to employ resources more efficiently. Despite the intrinsic interest of international comparisons, there are many reasons behind the limited development of studies looking to compare schools' results between countries, among which (i) the lack of reliable datasets and (ii) the substantial differences in institutional (countryspecific) settings. In this paper, I will try to overcome both of these limitations, first by using PISA 2012 data (OECD, 2014), which is well-regarded as an authoritative source of comparison for educational achievement across the world.

To the best of our knowledge, only three previous studies exist, which attempted to compare the performance/efficiency of schools in several countries, and just one has been published to date in an academic journal. We can thus define this literature at its very beginning. Wilson (2005) used the first edition of PISA (year: 2000) to answer the questions regarding which transitioning countries were more efficient in providing educational services, however including all developed and developing countries in the same empirical analysis. When focusing on the subsample of transitioning countries, he found that most efficient schools (on average) are in Macedonia, whilst the least efficient ones are Romanian. Sutherland et al. (2009) focused on the PISA 2003 dataset; their attention is not specifically on developing countries, and included instead mainly OECD countries in the empirical analysis. They conclude that PISA test scores in the selected subjects (reading, mathematics and science) can be improved by between $5 \%$ and $10 \%$, without the necessity of investing more resources in the educational systems. While the study uses both non-parametric and parametric techniques, the main results commented are those obtained with the latter. Through a secondstage analysis, the authors claim that some factors are associated with lower levels of efficiency, such as small school size, tracking students by ability and residence-based selection. Agasisti \& Zoido (2018) studied the efficiency of schools in 30 countries with a high level of cumulative spending on education (both OECD and not) through PISA 2012 data, and estimated a substantial degree of inefficiency, ranging from $32 \%$ in Slovenia to 
$16 \%$ in Singapore (in both cases, the reported values is a within-country average of schools' scores). The authors employed both parametric and non-parametric techniques, and the results are well correlated suggesting a general robustness of main findings. Also in this case, a second-stage regression has been utilised for exploring factors that are statistically correlated with efficiency scores, and the importance of characteristics of students' population, as well as some school practices (for instance, extracurricular activities) have been found as important. The present paper extends the knowledge beyond these previous contributions for three main reasons: (i) it considers PISA 2012 data, which is the most recent available, (ii) it analyses only low-income and developing countries - so, it focuses on their specific characteristics - and (iii) it deeply explores heterogeneity within and between countries.

With the aim of exploring the efficiency of schools, it is necessary to specify the kind of theoretical framework within which measuring schools' inputs (resources), activities (processes) and outputs (academic achievement). Considering a generic educational production process for an individual $\mathrm{i}$-th in the $\mathrm{j}$-th school, her achievement can be modelled as:

$y_{i j t}=f\left\{y_{i j(t-1)}, \overline{X 1}_{i j t(t-1)}, \overline{X 2}_{j t(t-1)}, \delta_{i}, \varepsilon_{i j}, \epsilon_{j}\right\}$

where $y_{i j t}$ is a measure of achievement score at time t, $y_{i j(t-1)}$ is an indicator of prior achievement, $\overline{X 1}_{i j t(t-1)}$ is a vector of student-specific characteristics (which also includes information about student's background, see (t-1)), $\overline{X 2}_{j t(t-1)}$ measures the school-level factors (including those of schools attended in the past, $\delta_{i}$ is a student's unobservable structural specificity (for instance, her innate ability), $\epsilon_{j}$ is a school-fixed effect (i.e. the factor that absorbs all relevant, unobservable school factors that are affecting achievement) and $\varepsilon_{i j}$ is a random error in estimation. If focussing the empirical analysis to the school level (i.e. using the school as a unit of analysis) ${ }^{2}$, the study of the educational production function (EPF) allows considering how efficient are the schools, on average, in employing their inputs (resources) for obtaining the output (students' achievement); in formal terms:

$y_{j}=f\left\{y_{j(t-1)}, \overline{X 2}_{j t(t-1)}, \epsilon_{j}\right\}$

where the various factors of this relationship are defined as above. In this setting, it is possible that not all the schools are equally able to maximize their (students') results, even in presence of observable inputs equal. In this setting, $\epsilon_{j}$ is assumed to include also an efficiency differential, so that $y_{j}$ can differ across schools exactly because of their different efficiency. This paper deals with this topic, and provides an estimate of the efficiency for a sample of schools included in the PISA 2012 dataset. In this research, we are particularly interested in relating performance of schools (i.e. their average academic results) with their

\footnotetext{
${ }^{2}$ While student-level data is often preferable for analysing the effects of policies and/or practices, it has been empirically demonstrated that the use of aggregated school data is useful for exploring some school-level interventions (Jacob et al., 2014), and this is the case as the efficiency concept is defined using the school as the level of analysis.
} 
available resources. In other words, we are not primarily targeting the performance of schools per se, but instead their efficiency, that is their ability to maximize the performance given the resources at their disposal. Such definitions of performance and efficiency are then used this way in the remainder of this research.

The research questions of this paper are two, and refer to the school operating in 28 lowincome and developing countries, selected among those that participated to OECD-PISA 2012:

- How is the relative (average) efficiency of the schools analysed in these 30 countries?

- Which are the factors (i.e. school-level features and student populations' characteristics) that are statistically associated with higher/lower efficiency scores?

Answering these questions is crucially important for policy purposes. First, providing a picture about the relative efficiency of schools in these countries represents an essential first step for judging the achievement levels in a more realistic way - i.e., considering the amount of resources invested in the sector together with performance. Second, in searching for the best "value for money" of educational practices, efficiency analysis can suggest potential interventions to be promoted at country (system) level, and/or specific activities that single school managers can be interested about.

The paper is organised as follows. In the next section $\S 2$, we describe the dataset, and the methodology employed for efficiency analyses. Section $\$ 3$ illustrates the results, while section $\S 4$ concludes, through a discussion of policy and managerial implications.

\section{Data and Methods}

\subsection{Data}

All data come from the 2012 edition of the Programme for International Student Assessment (PISA) of OECD. We focus the attention to the countries for which the cumulative expenditure on education per student (aged 6-15) is lower than 50,000\$ PPP, as defined by OECD (2013). In this perspective, we are not considering only developing countries as usually defined, but instead even "low-income" countries, i.e. countries which spend a limited amount of money on primary and secondary education because of their relatively low levels of Gross Domestic Product. All across the paper, we then use the definition "developing and low-income countries", and we are aware of potential differences between them. Later in this work, we also provide the results illustrating efficiency scores separately for countries in different continents.

While the original PISA dataset is built at student-level, we aggregate all the data at school level $^{3}$, given that the empirical analysis has been conducted using schools as the unit of analysis. In this perspective, efficiency is calculated for each school as organizations and we do not analyse data of single students. The educational process is then modelled at school level considering the resources employed by each school (financial and human) to produce results (academic achievement).

\footnotetext{
${ }^{3}$ PISA uses weights at student and school level to guarantee representativeness of the selected sample of students at country level. When analysing data, it is necessary to consider the weights at the appropriate level of aggregation. Given that our paper aims at considering the efficiency of schools (and not analyses at student level), in the process of aggregating data at school level we used the students' weights (variable name: W_FSTUWT).
} 
After having defined inputs and outputs (see below), we dropped the schools for which some of them are missing (around 10\%); at the end, the dataset comprises 6,818 schools in 28 countries. The choice of focusing on PISA 2012 data also allow comparing the results with those obtained by Agasisti \& Zoido (2018) in a paper where the analysis deals with richer countries.

The selection of inputs and outputs has been guided by the existent literature in the field. More specifically, the educational process is modelled as one in which each unit (i.e. the school) receive a given amount of inputs - namely, human and financial resources - and use them for "producing" as much output (i.e. students' achievement) as possible. As proxies for inputs, the following ones have been used: the (inverse of) students:teachers ratio (StRatio), which measures the quantity of human resources, and the number of computers per student (Computer_n) as an indirect measure of schools' facilities. In addition, the students' average index of socioeconomic status (ESCS - Economic, Social and Cultural Status) has been included among inputs, and it serves as control for students' background and previous academic (cultural) history ${ }^{4}$. As measures of outputs, both test scores in mathematics and reading are considered ${ }^{5}$ ( $p v$ lmath and pvlread, respectively).

In the columns (a)-(f) of the table Annex_1, the descriptive statistics for inputs and outputs of the 6,818 schools under analysis are reported. As it can be easily seen, the school-average ESCS is much lower than the OECD average - which is set to 0 by construction, and this element confirms that in these countries the students' socioeconomic and cultural background is a major factor explaining low academic performances. Differences between countries are present, thus; for instance, in the United Arab Emirates and Qatar average schools' ESCS is higher than zero, while in Indonesia, Turkey and Viet Nam it is well below -1.5. The availability of computers in the schools analysed is around 0.4 computers per student; this value ranges between less than 0.2 on average in Turkey, Indonesia and Brazil to more than 0.8 in Kazakhstan, Lithuania, Latvia and Qatar. StRatio is on average 0.09 (meaning that there is one teacher for every 11 students), again with striking differences: for instance, the indicator's value is 0.05 in Thailand, and 0.15 in Argentina. Test scores in mathematics and reading are well below the OECD average: recalling that the latter is set at 500 points, in the countries under analysis they are 417 and 424, respectively. While schools in some countries show results that, on average, are not far from OECD mean (for example: Viet Nam, Croatia, Turkey, Hungary), there are also countries in which schools' results are very low, such as Peru, Qatar and Brazil.

\footnotetext{
${ }^{4} \mathrm{We}$ are aware that the lack of measures for prior achievement is a strong limitation for our analysis. At the same time, we clearly indicate that we are not analyzing the data in a value-added perspective. In other words, we are estimating the efficiency of schools in producing the current levels of performance, knowing that some of this efficiency could be driven by students sorting across schools by ability. In any case, controlling for ESCS of students reduces this risk substantially. Given that there is strong statistical correlation between ESCS and current test scores as measured by PISA (school average is around $0.6^{*}$ for both reading and mathematics test scores), we can assume that such correlation also held in previous academic results (it is only in this sense that we can consider ESCS as a proxy for prior academic achievement, at least partially).

${ }^{5}$ PISA scores are built - for each student - using five plausible values (PVs). As described in the PISA technical reports, the best way to use them is to employ one at a time. This is the strategy used here, that is to say outputs are measured by the first plausible value of the test score; through robustness checks, I show that nothing changes when considering alternative PVs instead of the first (results available on request).
} 
A further step undertaken in this paper is to explore factors that are potentially associated with the efficiency scores. The subsection about methodology describes the econometric technique employed for this purpose. The variables chosen for this task can be classified into five groups: (i) students' characteristics, (ii) schools' general features, (iii) resources materials and school time, (iv) teachers' characteristics and (v) practices and processes. The definitions for each of the different variables included in the groups are reported in the Table Annex_2, panel A, and their descriptive statistics are in panel B. The indicators, described below, are a subset of the wider list of interesting variables included in the PISA datasets; for choosing among the various variables, we relied upon the suggestions derived from existent literature on educational efficiency (see the extensive literature review provided by De Witte \& Lopez-Torres, 2017). Moreover, on a practical ground, a fine-tuning of the empirical model has been realised, with the aim of maximizing its explanatory power in the international comparison. We are aware that we cannot claim causality about the relationship between efficiency scores and the variables employed in the second-stage, as we do not test the separability condition (see Daraio et al., 2018). Still, the statistical associations showed in this research can add to the bulk of limited existence evidence for the efficiency of schools in low-income countries.

Among the students' characteristics, the variables are: the proportion of female students in the school (female), the number of hours devoted to homework set by teachers, as selfreported by students (hwork_h), the proportion of repeaters (repeater), the proportion of students who self-reported to have skipped at least one day at school (st_truancy), the standard deviation - within school - of students' ESCS, which intends to capture diversity or homogeneity of student body (ESCSsd) and of students' math scores as a proxy for the homogeneity of students' academic level (pvlmathsd), and lastly the proportion of students who self-report that their parents believe that "mathematics if very important" (pm_important $)^{6}$. Taken together, these variables aim at capturing if a school's efficiency (the ability of maximizing the students' achievement levels, given the available resources) is influenced or not by a set of students' personal characteristics beyond their socioeconomic background - the latter being included among inputs through ESCS.

Schools' general features indicate whether the school is: ISCED2 (isced2) or ISCED3 ${ }^{7}$, if its orientation is general/academic (orgen) or vocational/technical, if the schools is public or not (private), if it is located in a rural area (village). Also, the number of students (divided by 10) is in this group (size).

Two variables constitute the group of resources: an index built by PISA team about the adequateness and quality of available instructional resources (sc_matedu) and the minutes of lessons devoted to mathematics, per week (mminutes). While the efficiency model takes the quantity of human and material resources into account, these two additional indicators aim at measuring more the "quality" of resources and their use, and can be used to explore whether

\footnotetext{
${ }^{6}$ It is worth noting that many of these variables refer to mathematics, although the test scores used as outputs are those in mathematics and reading. This specific feature is because he main focus topic of PISA 2012 was mathematics - so, the student questionnaire was centered on students' motivations and attitudes towards mathematics specifically.

${ }^{7}$ In the International Standard Classification of Education (ISCED) proposed by UNESCO, ISCED 2 is lowersecondary education, and ISCED 3 is upper-secondary education.
} 
these dimensions somehow influence efficiency differential between schools. This topic is particularly interesting given that some economic literature, dating back to Hanushek (1989), failed to find correlations between schools' academic results and the quantity of their available resources (which corresponds to the definition of efficiency used in our paper).

The indicators that have been chosen for describing teachers' workforce are: two indexes built by the PISA team about the teachers' participation to school's decisions (tc_part) and about the teacher-related school climate factors - as, for example, satisfaction, motivation etc. $\left(t_{-}\right.$clim). In addition, the proportion of teachers who participated to formative programs in the last year is considered as well (t_develop), as a proxy for the quality and update status of human capital involved in teaching activities.

Lastly, main practices and processes are measured by a dummy for indicating if the school makes its students' achievement scores public (accountability_1), and another dummy for schools whose principal reports that the school is competing for students with other two or more "competitors" (competition). The index, built by PISA team, about the number and types of extracurricular activities (extracur) is included as well.

\subsection{Methodology}

Efficiency is analysed by means of Data Envelopment Analysis (DEA). This well-known technique has been developed for calculating a frontier of efficient Decision-Making Units (DMUs, in this case, schools), based on observed combinations of inputs and outputs. Mathematically, efficiency of each $\mathrm{j}$-th school is defined as:

$E f f_{j}=\frac{\sum_{n=1}^{N} y_{n j} \alpha_{n}}{\sum_{m=1}^{M} x_{m j} \beta_{m}}$

where $y_{n j}$ is the vector containing the $\mathrm{n}=1, \ldots \mathrm{N}$ outputs (for instance, test scores in different subjects) and $x_{m j}$ is the vector containing the indicators about the $\mathrm{m}=1, \ldots \mathrm{M}$ inputs (as, for example, number of teachers and facilities); $\alpha_{n}$ and $\beta_{m}$ are the weights associated to the $\mathrm{N}$ outputs and $\mathrm{M}$ inputs. The DEA technique builds on a linear programming algorithm that maximizes this ratio between outputs and inputs for each school, in practice defining the weights that makes $E f f_{j}$ the highest as possible (for technical details about the methodology, see Cooper et al., 2007). If $E f f_{j}$ the j-th school is defined as efficient (and is considered to be positioned on the frontier); if $E f f_{j}<1$ the school is considered as inefficient (i.e. it stands below the frontier), and the distance from 1 measures the degree of inefficiency. The methodology is completely deterministic, in the sense that it attributes all the deviation from the frontier to inefficiency - there is no random error estimated. As a key advantage, DEA allows employing multiple outputs and multiple inputs at the same time, and this feature is particularly important for settings like education where schools "produce" different kinds of achievement using jointly different types of inputs (i.e. teachers, financial resources, students themselves, etc.). In this paper, we calculated a statistically-modified version of DEA scores, allowing for them having a confidence interval; following Simar \& Wilson (2000) a bootstrap procedure has been implemented (2,000 replications), to measure the bias in the score estimation - due to not observing the Data Generation Process (DGP) of inputs and outputs, 
and lack of complete observation of all schools in the various countries. Consequently, the scores that are commented for judging schools' efficiency, in this work, are those labelled as bias-corrected - those from which the effect of bias is subtracted (for more technical details, see also Thanassoulis et al., 2008). The package FEAR for the $\mathrm{R}$ software has been used for estimation (Wilson, 2008). The DEA model used is output-oriented (i.e. each unit is assumed to maximize outputs, given the available inputs) and allows for variable returns to scale (i.e. each school is compared against a frontier of efficient units where the different size - amount of input - is taken into account).

For analysing the factors associated with efficiency scores, we do not rely on a second-stage regression that could be flawed by some key methodological problems. Instead, we follow the double-bootstrap procedure suggested by Simar \& Wilson (2007). Specifically, we employ the algorithm \#1 proposed by the authors, but using the bias-corrected efficiency scores obtained through the methodology illustrated above (in this vein, the results are almost identical to those derived by using the algorithm \#2). In practical terms, we proceeded as follows:

- We first calculate the bias-corrected efficiency scores, following the procedure indicated in Simar \& Wilson (2000);

- We then regress the efficiency scores on school-level factors selected for the secondstage analysis; employing a bootstrap procedure (1,000 replications), we obtain estimates of the distribution of coefficients, as well as their bias-corrected estimation and confidence intervals.

The command SIMARWILSON developed in STATA has been used for the estimation of the second-stage (Tauchmann, 2016). As anticipated, still our methodology does not allow the testing of the separability condition, i.e. that factors used for the second-stage truncated regression do not impact also efficiency scores estimated in the first stage. In any case, tests for such assumption have been developed only recently (see Daraio et al., 2018) and could be applied in future research dealing with the issue of estimating the causal effect of some environmental factors on schools' efficiency.

\section{$\underline{3 . \text { Results }}$}

\subsection{Efficiency scores: international frontier}

The bias-corrected efficiency scores of schools are reported in the table 1 (column e). The average efficiency is found at 0.699 , meaning that, when considering best-performing schools in the sample, on average the others can improve test scores by $30 \%$ with the currently available resources. Such figure suggests the room for considerable efficiency improvements, especially when recalling that the best-in-class are schools operating in low-income and developing countries (thus, the relative efficiency scores are not computed comparing schools with counterparts in wealthy countries). Standard deviation, as well as the range of minimum and maximum values, indicates that relevant variation both between and within countries can be detected. For instance, average efficiency of schools in Viet Nam is quite high (0.834) and standard deviation relatively low (0.079); conversely, efficiency of schools in Qatar is low (0.609) and standard deviation relatively high (0.121), highlighting the presence of a wider distribution of efficient and inefficient institutions. A complimentary way of looking at the distribution of efficiency within country is in the figure 1 , which contains the boxplots of 
scores. The two cited countries - Viet Nam and Qatar - are at the extreme right and left of the figure, respectively, because the plots are ordered from the lowest to the highest median efficiency; it can be seen how the whiskers are much longer for Qatar than Viet Nam, confirming a higher degree of heterogeneity of schools' efficiency in the former country. The visual representation is also useful for showing other cases, such as the ones of Malaysia (low median efficiency, narrow distribution) and Hungary (high median efficiency, wide distribution). Moreover, in some countries there are outliers - i.e. schools with an extraordinarily high/low efficiency score when compared with the most part of distribution of the country, see for example the cases of Tunisia, Indonesia and Mexico. In one sense, this graphical/statistical tool could be used to detect schools with particular characteristics to be investigated or discussed, with the aim of understanding the particular status of high/low efficiency and derive specific interventions or managerial implications. From Table 1, it is also evident how schools with high proportion of relatively better-off students (advantaged schools) are on average more efficient than their disadvantaged counterparts, with differences that range between 5\% and 40\% (see columns a-d) - we discuss this issue further in the next paragraphs.

In the figure 2 , it is possible to individuate how efficiency is able to capture a different perspective than pure performance. On the horizontal axis, the DEA efficiency score is reported, while the vertical axis has the PISA 2012 score in mathematics (the figure contains country-average data). We chose to use performance in mathematics as a reference because PISA 2012 edition considers mathematics as the main subject tested (in any case, the resulting graphs are similar when using reading instead of mathematics). While a general positive correlation between the two indicators can be observed, it can also be noted that some countries depart from this relationship. For instance, on average Turkish schools are relatively efficient, despite a relatively low score in mathematics, and this result suggests that they serve disproportionally disadvantaged students with few resources, but are able to make the most in terms of academic achievement. Instead, schools in Lithuania are not highly efficient, despite a relatively higher average score in mathematics, so the judgment is that they can improve more their scores with the same resources and the kind of (relatively) better-off students they serve.

[Table 1, Figures 1 and 2] around here

In subsequent analyses, we calculated how many schools are included in the group of most and least efficient institutions, defined as those whose efficiency score is in the $90^{\text {th }}$ and $10^{\text {th }}$ percentile of scores' distribution, respectively. The objective of this focus is to characterize the frontier of efficient units, especially by checking whether schools operating in specific countries are more likely than others to influence the efficiency benchmark, or lagging well behind the efficiency standards. This is the case, indeed. The table 2 reports the number of very efficient and inefficient schools in the column (a) of both panels A and B. Column (h) calculates the proportion of (in)efficient schools for each country, while column (i) indicates the proportion of the country's schools in the group of most(least) efficient ones. The information about the proportion of in/efficient schools by country is also graphically represented in the figure Annex_3. Mexican schools alone count for almost 20\% of the group 
of efficient (but also 8.8\% of the inefficient units), and Vietnamese schools account for an additional $12.5 \%$ - while having just 1 school in the group of least efficient. However, considering these two countries only $13 \%$ of Mexican schools are efficient, versus the $69 \%$ of Vietnamese ones. Other interesting cases of countries where a high proportion of schools are classified as in the group of most efficient are: Turkey (36.6\% of its schools), Hungary (27.6\%) and Croatia (25.5\%). On the other side of efficiency spectrum, there are: Qatar, where $41.9 \%$ of its schools are classified as inefficient, Peru (35.8\%), Argentina (31.4\%) and Jordan $(30.7 \%)$.

Other interesting insights from table 2 deal with the different profiles of efficient and inefficient schools. For instance, while most schools with an efficiency score in the $90^{\text {th }}$ percentile have high scores in mathematics and reading, the 48 Brazilian and 170 Mexican most efficient schools are so classified despite their relatively low achievement score, because their students have very low socioeconomic background (-0.493 and -0.843 , respectively). Again, the 3 Peruvian most efficient schools report high scores in reading, but not mathematics; and the 4 Malaysian most efficient schools have a relatively low number of computers per student. Analogous reflections can be done for the schools labelled as most inefficient (panel B): the 57 inefficient schools in Qatar have low scores despite the high average level of students' background (ESCS> 0.13), while the 2 inefficient schools in Latvia have not extremely low scores, but obtained using a high intensity of resources, i.e. the number of computers.

This analysis of heterogeneity across countries could be replicated by looking at efficiency differentials within country - not reported here - and can really be purposeful for its policy and managerial consequences. Above all, these descriptive statistics of most and least inefficient schools indicate that there is not a unique way of making the most with the available resources, and in the other sense that educating better-off students and having higher levels of human and structural resources is not enough alone to secure good performances. The comparison with other schools, in a benchmarking spirit, can help in transforming these reflections into practical empirical analysis about the levels of inputs and outputs to be changed for pursuing higher efficiency.

[Table 2] around here

Therefore, the evidence presented above suggests that efficiency is somehow related with the average socioeconomic status of the schools, in other terms serving better-off students not only leads to higher (school-average) test scores, but also to higher efficiency. As a clue, see from table 3, panels A and B, that schools with efficiency scores in the $90^{\text {th }}$ percentile have students with better background than the average - measured by ESCS - the contrary holding for schools with scores in the $10^{\text {th }}$ percentile. The intuition is that educating high-SES students allows obtaining academic scores that are proportionally (not only in absolute) higher than those of the schools serving low-SES students. For investigating quantitatively this pattern, I build an indicator about the students' (school-average) dis/advantaged status. Operationally, I computed an indicator for classifying the school as "advantaged", "average" or "disadvantaged" depending if its average ESCS index is in the $33^{\text {rd }}$, between $33^{\text {rd }}$ and $66^{\text {th }}$, or in $66^{\text {th }}$ percentiles of ESCS distribution within country (this way, the index measures the 
relative advantage compared with the student populations of other schools in the same country). The analysis of eventual differences between the three groups of schools is reported in the figure 4, and clearly demonstrates that schools where students have a more favourable socioeconomic background are also more efficient - the difference between the peaks of the three distributions is similar, and approximately equal to 0.1 efficiency points. Interestingly, however, there are some schools in the tails of the distributions, namely advantaged schools with very low efficiency scores and disadvantaged but very efficient schools.

The efficiency differentials between disadvantaged and advantaged schools are not homogenous across countries, however. The figure 5 illustrates the distributions of efficiency scores for the three categories of schools, by country. From this graphical analysis, it can be noted that some countries are characterized by striking differences as, for instance Bulgaria, Chile, Greece, Hungary and Uruguay. Instead, some other countries like Brazil, Indonesia, Kazakhstan and Mexico present small differences in the efficiency distribution of advantaged and disadvantaged schools. Albeit no conclusion can be drawn by simple analyses of distributions, one potential hypothesis is that school quality matters more in countries where the differences between schools with different ESCS is lower - indeed, it would mean that students' SES matters less in determining schools' efficiency. A quantitative estimation of the efficiency differences between advantaged and disadvantaged schools is given in the columns (a)-(d) of the table 1 , as noticed above.

[Figure 3 and 4] around here

\subsection{The factors associated with efficiency}

In the table 3, we illustrate the results from the second-stage regression where the dependent variable is the bootstrap, bias-corrected efficiency score and the covariates are the schoollevel characteristics listed in the section $\$ 2.1$. As described in the section about methodology, the estimation is obtained through the robust, double-bootstrap method proposed by Simar \& Wilson (2007).

Students' average characteristics do matter; even net of the effect of average ESCS (which is included in the inputs, indeed) the efficiency of a school is positively or negatively affected by the average features of its population of students. For example, the proportion of females is positively correlated with the efficiency scores, while the contrary holds for the proportion of repeaters and the proportion of students who report to have skipped at least one day (st_truancy). Two indicators are of particular interest here, namely the proportion of students who report that their parents consider mathematic as "important" (pm_important), and the number of hours devoted to homework set by teachers (hwork $h$ ). Both variables can be interpreted as an indirect measure of students' motivation, and if more motivated students are in the school, its efficiency tends to be higher - suggesting that, all other resources equal, it is easier to obtain school-average higher scores from more motivate students. The negative sign attached to the standard deviation of ESCS within school (ESCSsd) suggests that teaching more homogeneous groups of students is more efficient. The positive coefficient for the standard deviation of scores ( $p v 1$ mathsd) indicates that more diverse schools - in terms of academic abilities - can be more efficient. 
Turning to the schools' institutional features, lower-secondary ones (isced2) are less efficient, on average, while those with an academic, general orientation are more efficient (orgen). Private schools are slightly more efficient ${ }^{8}$, while institutions operating in a village (that is, in a rural context) are less efficient. There is also a small positive correlation between efficiency and size (number of students), indicating the presence of some kind of scale effects, albeit the magnitude of the coefficient is very low.

The two variables that are used as proxies for the quality of resources (an index of the principal feelings about resources' adequateness, sc_matedu and the time devoted to mathematics in class, mminutes) are positively correlated with efficiency (although the latter is only marginally significant and with a very small coefficient). On one side, this evidence highlights that resources can matter on schools' performances, at least in these low-income and developing countries - while the role of resources on schools' results is much more controversial in developed countries, see Hanushek $(1989 ; 1995)$. Also, the finding points at stressing the importance of the quality of resources, in addition to their amount.

The group of the three variables that measure teachers' characteristics (tc_part, $t$ _clim and t_develop) are positively correlated with schools' efficiency, however only t_clim is statistically significant. Institutions where the climate factors related to teachers are positive (i.e. the principal feels that school climate is better because of the teachers' contribution) are also more efficient.

Lastly, among the four factors related to "practices and processes", only competition contributes positively to efficiency. The interpretation is that the degree of competition - i.e. the principal reports that the school competes with two or more schools for the same students - can have a beneficial effect on the way in which resources are used for obtaining higher academic results, in line with some predictions of the economic literature and international evidence on school choice and competition (Woessmann, 2007).

Overall, the general image that emerges from the analysis is that factors related to students' characteristics have a major role in explaining schools' efficiency. This is a crucial finding, because not only it reinforces the evidence that socioeconomic background of students do influence the performance (Haveman \& Wolfe, 1995) - indeed, we account for this by including ESCS among inputs - but also clarifies that it is easier to make the most with advantaged students (i.e. not repeaters, motivated etc.) than with disadvantaged. Other school factors do correlate with efficiency, for instance the teachers-related climate and the degree of competition. These are the main elements that can be evaluated by principals to try efficiency improvements, although the magnitude of the effect is somehow lower than that associated to students' features. Nevertheless, it is important to underline that these results hold when considering all the schools (countries) together, and must be interpreted as "average" effects or correlations. It is perfectly reasonable that for a specific school, and/or in a given country, the set of factors that is better able to determine the efficiency scores is slightly - or even substantially - different. In other words, the model for the second-stage regression has not been chosen to maximize the explanatory power of single schools or

\footnotetext{
${ }^{8}$ In the context of developing countries, the claim that private schools outperform public ones was suggested in a comparative perspective since Jimenez et al. (1991).
} 
countries, but for identifying the factors that are more associated with efficiency in the international perspective.

[Table 3] around here

As a further aspect of the empirical analysis, we explored the relationships between efficiency scores and an indicator that is considered as a proxy of inclusion, i.e. the proportion of students whose proficiency level is below level 1. This level of proficiency (=358 PISA points in mathematics) is defined by OECD as the baseline level of knowledge for living in modern and developing societies ${ }^{9}$. The aim of this analysis is to investigate whether efficiency is negatively or positively correlated with this proxy for inclusion/equity; the results are graphically represented through boxplots in the figure 5. Most efficient schools (up in vertical axis) are those where the proportion of low performing students is lower (left in horizontal axis). Obviously, there is something mechanic in this relationship: all else equal, the higher the proportion of poor performers, the lower the PISA score and the lower is efficiency. However, in the efficiency analysis is not all equal: it could be the case that the average PISA score of a school comes from a narrow distribution around the mean, while that of another school could be wider - with a high proportion of low performers. With the same mean, the former school can be judged as more "equal" or "inclusive" of the latter, because is able to obtain the same academic results with less students left behind. Thus, in this sense it is worth it to analyse this relationship between efficiency and equity, and the findings corroborates the intuition that they are somehow complimentary - in other words, the most efficient schools are also the most inclusive ones. Observing the whole distribution - and the confidence intervals above all - is clear that, however, there relatively highly efficient schools with high proportion of low performances, as well as relatively lowly efficient ones with few poor performing students, again suggesting that school-specific characteristics interact to determine the efficiency-equity combination of a given institution.

[Figure 5] around here

The final step of our analysis is to give further evidence of the heterogeneity across countries. Indeed, we classify under the term "low-income and developing" countries which are very different under various aspects, such as tradition, culture, development level, etc. A simple way to analyse countries' results in more homogeneous and comparable way is to divide them by continent. Thus, we report the efficiency scores by countries in Table 4 and Figure 6 . It must be noted here that we have only one African country (Tunisia) and that we group together Russia and Turkey under the label "Eurasia". Looking at the statistics, some differences actually emerge. The most striking evidence is that schools in European and Eurasian countries obtain higher efficiency scores, with those in Africa (Tunisia) reporting the lowest scores. Figure 5 also highlights that distributions (not only means) of efficiency

\footnotetext{
${ }^{9}$ The exact definition is (OECD, 2014; p. 61): "At Level 1, students can answer questions involving familiar contexts where all relevant information is present and the questions are clearly defined. They are able to identify information and to carry out routine procedures according to direct instructions in explicit situations. They can perform actions that are almost always obvious and follow immediately from the given stimuli".
} 
scores are different. As a matter of fact, such differences could reflect factors that are beyond the managerial efficiency of schools, and could be related to welfare regimes or other institutional factors that vary across continents with very different traditions and settings. These differences should be explored in future studies which would consider more explicitly the role of sovranational elements that shape educational provision and schools' productivity.

\section{[Table 4 and Figure 6] around here}

\section{Discussion, policy implications and concluding remarks}

In this paper, we estimated the efficiency for more than 6,800 schools in 28 low-income and developing countries, using a bootstrap version of DEA as method, and PISA 2012 as data. To the best of our knowledge, this is the first attempt of such an efficiency analysis conducted in an international perspective, with specific reference to low-income countries. The exercise is very informative as it turns out having implication both for policy makers and schools' managers.

The first policy lesson is that, although there are relevant differences between countries in schools' average efficiency scores (for instance, Vietnamese schools are on average much more efficient than those in Qatar), the distribution of the scores within countries is significantly larger. Even in the countries where schools' mean efficiency is lower, there are some schools that are able to make the most with their available resources. In this sense, conducting benchmarking analyses within each country is useful per se, because it allows seeing (and measuring) the degree of internal (country-specific) heterogeneity in efficiency results.

Therefore, international comparisons are meaningful because they set higher targets for all schools, independently of the geographical and institutional context where they operate. In such a perspective, the international benchmarking is a great opportunity to enlarge the knowledge of practices and actions that make easier the transformation of inputs (human and financial resources) into output - i.e. students' academic achievement. Observing the characteristics of the most efficient schools (nationally and internationally) would be an interesting by-product of this work, and can be suggestive for policy makers to promote changes in schools' operations to be more similar to those of efficient ones - in a "cleverly copying" approach.

On one side, the message emerging from the second-stage is that schools in different countries have different ways of being efficient, and the same holds within country. In other words, the strategies, practices and activities that must be used to maximize the achievement levels are dependent of the specific student population that each school must serve. To the extent to which this is true, a pre-requisite for schools' efficiency is their autonomy, i.e. the possibility of experimenting different educational models, extracurricular activities, instruments for competing with alternative schools, etc. This suggestion would also be coherent with the finding of some previous research, that points at suggesting autonomy as a leverage for improving students' results (Jimenez \& Lockheed, 1995), and challenges the view suggested by Hanushek et al. (2013), for whom: "At low levels of economic development, increased autonomy actually appears to hurt student outcomes, in particular in decision-making areas related to academic content." (p. 227). In policy terms, the challenge 
of autonomy should be accepted as a pathway for trying, in the short-medium term, to promote schools' ability of finding their way to increase efficiency.

At the same time, some school-level factors appear as correlated with efficiency in the majority of country and settings, and should be carefully evaluated by national policy makers as possible directions towards which providing incentives for schools. For instance, schools where principals consider the quality of educational resources as "adequate" are also more efficient. In this sense, it can be the case that the quality - and not only quantity - of resources do play a role in favouring schools' action towards increasing achievement. Also, the indicator about teachers-related climate is positively associated with higher efficiency scores, and this element claims for a constant attention to the quality of human resources employed in the educational activities. Lastly, schools where principals feel competitive pressures also obtain higher efficiency scores. There are several potential explanations for these results (which, however, are consistent with those reported since Woessmann, 2003 for developed countries); the main resides in the incentives that the schools more open to the external context have for conducting their activities more efficiently. Available data, unfortunately, prevents the possibility of exploring these mechanisms more profoundly.

The most part of efficiency's determinants remains unexplained, thus. On one side, it is likely that the "technology" of schools that are more efficient in translating resources into achievement resides in teachers. Indeed, a robust finding of the literature is that teachers do make an enormous difference for students' achievement (Harris \& Sass, 2011) - and, if considering the resources as given, more effective teachers translate into more efficient schools. This being the case, the variables that measure teachers' characteristics in PISA 2012 are still quite raw and imprecise - and the necessity of improving them certainly represents a short-term challenge for PISA. Therefore, improving the details about the internal schools' practices (such as governance, decision-making processes, etc.) would also help in clarifying potential factors associated with higher/lower levels of efficiency.

This research has some limitations, too. Among them, I did not consider prior achievement (this information is not included in the PISA datasets), so that the robustness of efficiency scores relies upon the ability of ESCS to capture prior academic history of students. Also, the model only considers cognitive skills as outputs (i.e. the PISA test scores) and did not include measures of non-cognitive skills. Albeit some indicators of this kind are present in the dataset, such as proxies for self-esteem and problem-solving attitude (see OECD, 2013) I did not consider sufficiently robust to be paired with the test scores. Part of these weaknesses are intrinsic to the kind of methods used here, while others are due to data limitations; hopefully, future research will relax these constraints, and would be able to stimulate further advancements in the knowledge of the field.

A natural extension of this work consists in applying the same analyses to OECD PISA 2015 and 2018 data (the latter will be available in late 2019), with the aim also to show whether the efficiency of schools in the selected countries improved or declined over time. Such variations in average efficiency levels could also be related to new policies and interventions eventually realized in the countries, with the aim to increase the productivity of the educational sectors. 


\section{$\underline{\text { References }}$}

Afonso, A., \& St Aubyn, M. (2006). Cross-country efficiency of secondary education provision: A semi-parametric analysis with non-discretionary inputs. Economic Modelling, 23(3), 476-491.

Agasisti, T. (2014a). The efficiency of public spending on education: an empirical comparison of EU countries. European Journal of Education, 49(4), 543-557.

Agasisti, T. (2014b). How does schools' efficiency look like across Europe? An empirical analysis of Germany, Spain, France, Italy and UK using OECD PISA2012 data. SIEP Working Paper.

Agasisti, T., \& Zoido, P. (2018). Comparing the Efficiency of Schools Through International Benchmarking: Results From an Empirical Analysis of OECD PISA 2012 Data. Educational Researcher, 0013189X18777495.

Al-Enezi, M., Burney, N. A., Johnes, J., \& Al-Musallam, M. (2010). An assessment of efficiency of public schools in Kuwait using data envelopment approach (DEA) and Tobit regression. Journal of Development and Economic Policies, 12(2), 7-33.

Bogetic, Z., \& Chattopadhyay, S. K. (1995). Efficiency in Bulgaria's schools: a nonparametric study. World Bank Policy Research Working Paper, (1422).

Burney, N. A., Johnes, J., Al-Enezi, M., \& Al-Musallam, M. (2013). The efficiency of public schools: the case of Kuwait. Education Economics, 21(4), 360-379.

Clements, B. (2002). How efficient is education spending in Europe?. European Review of Economics and Finance, 1(1), 3-26.

Cooper, W. W., Seiford, L. M., \& Tone, K. (2007). Data envelopment analysis: A comprehensive text with models, applications, references and DEA-Solver Software. Second editions. Springer, ISBN: 387452818, 490.

Daraio, C., Simar, L., \& Wilson, P. W. (2018). Central limit theorems for conditional efficiency measures and tests of the 'separability'condition in non - parametric, two - stage models of production. The Econometrics Journal, 21(2), 170-191.

De Witte, K., \& López-Torres, L. (2017). Efficiency in education: a review of literature and a way forward. Journal of the Operational Research Society, 68(4), 339-363.

Essid, H., Ouellette, P., \& Vigeant, S. (2010). Measuring efficiency of Tunisian schools in the presence of quasi-fixed inputs: A bootstrap data envelopment analysis approach. Economics of Education Review, 29(4), 589-596.

Gupta, S., Verhoeven, M., \& Tiongson, E. R. (2002). The effectiveness of government spending on education and health care in developing and transition economies. European Journal of Political Economy, 18(4), 717-737.

Hanushek, E. A. (1989). The impact of differential expenditures on school performance, Educational Researcher, 18(4), 45-62. 
Hanushek, E. A. (1995). Interpreting recent research on schooling in developing countries. The World Bank Research Observer, 10(2), 227-246.

Hanushek, E. A., \& Woessmann, L. (2008). The role of cognitive skills in economic development. Journal of Economic Literature, 607-668.

Hanushek, E. A., Link, S., \& Woessmann, L. (2013). Does school autonomy make sense everywhere? Panel estimates from PISA. Journal of Development Economics, 104, 212-232.

Harris, D. N., \& Sass, T. R. (2011). Teacher training, teacher quality and student achievement. Journal of Public Economics, 95(7), 798-812.

Haveman, R., \& Wolfe, B. (1995). The determinants of children's attainments: A review of methods and findings. Journal of Economic Literature, 1829-1878.

Jacob, R. T., Goddard, R. D., \& Kim, E. S. (2014). Assessing the Use of Aggregate Data in the Evaluation of School-Based Interventions Implications for Evaluation Research and State Policy Regarding Public-Use Data. Educational Evaluation and Policy Analysis, 36(1), 44-66.

Jiménez, E., Lockheed, M. E., \& Paqueo, V. (1991). The relative efficiency of private and public schools in developing countries. The World Bank Research Observer, 6(2), 205-218.

Jimenez, E., \& Lockheed, M. E. (1995). Public and private secondary education in developing countries: A comparative study (Vol. 309). World Bank Publications.

Johnes, J. (2004). Efficiency measurement. International Handbook on the Economics of Education, 613.

Lassibille, G., \& Tan, J. P. (2001). Are private schools more efficient than public schools? Evidence from Tanzania. Education Economics, 9(2), 145-172.

Leithwood, K., \& Menzies, T. (1998). Forms and effects of school-based management: A review. Educational Policy, 12(3), 325-346.

McDonald, J. (2009). Using least squares and tobit in second stage DEA efficiency analyses. European Journal of Operational Research, 197(2), 792-798.

Mizala, A., Romaguera, P., \& Farren, D. (2002). The technical efficiency of schools in Chile. Applied Economics, 34(12), 1533-1552.

OECD (2013), PISA 2012 Results: Ready to Learn: Students' Engagement, Drive and Self-Beliefs (Volume III), PISA, OECD Publishing. http://dx.doi.org/10.1787/9789264201170-en.

OECD (2014), PISA 2012 Results: What Students Know and Can Do - Student Performance in Mathematics, Reading and Science (Volume I, Revised edition, February 2014), PISA, OECD Publishing. http://dx.doi.org/10.1787/9789264201118-en.

Patrinos, H. A., \& Fasih, T. (2009). Decentralized decision-making in schools: The theory and evidence on school-based management. World Bank Publications.

Portela, M. C. A., \& Thanassoulis, E. (2001). Decomposing school and school-type efficiency. European Journal of Operational Research, 132(2), 357-373. 
Simar, L., \& Wilson, P. W. (2000). A general methodology for bootstrapping in nonparametric frontier models. Journal of Applied Statistics, 27(6), 779-802.

Simar, L., \& Wilson, P. W. (2007). Estimation and inference in two-stage, semiparametric models of production processes. Journal of Econometrics, 136(1), 31-64.

Simar, L., \& Wilson, P. W. (2011). Two-stage DEA: caveat emptor. Journal of Productivity Analysis, 36(2), 205.

Sutherland, D., Price, R., \& Gonand, F. (2009). Improving public spending efficiency in primary and secondary education. OECD Journal: Economic Studies, 2009(1), 1-30.

Tauchmann, H. (2016). SIMARWILSON: Stata module to perform Simar \& Wilson efficiency analysis. Statistical Software Components. S, 458156.

Thanassoulis, E., Portela, M. C., \& Despic, O. (2008). Data envelopment analysis: the mathematical programming approach to efficiency analysis. The measurement of productive efficiency and productivity growth, 251-420.

Wilson, P. W. (2005). Efficiency in education production among PISA Countries, with emphasis on transitioning economies. in World Bank Working Paper available at: http://upeg.eerc.kiev.ua/conf/papers/Wilson_Paul.pdf

Wilson, P. W. (2008). FEAR: A software package for frontier efficiency analysis with R. Socio-Economic Planning Sciences, 42(4), 247-254.

Woessmann, L. (2003). Schooling resources, educational institutions and student performance: the international evidence. Oxford Bulletin of Economics and Statistics, 65(2), 117-170.

Woessmann, L. (2007). International evidence on school competition, autonomy, and accountability: A review. Peabody Journal of Education, 82(2-3), 473-497.

Worthington, A. C. (2001). An empirical survey of frontier efficiency measurement techniques in education. Education Economics, 9(3), 245-268. 
Table 1. Efficiency scores, by country

\begin{tabular}{|c|c|c|c|c|c|}
\hline Country & $\begin{array}{c}\text { Disadvantaged } \\
\text { schools }\end{array}$ & $\begin{array}{l}\text { Average } \\
\text { schools }\end{array}$ & $\begin{array}{c}\text { Advantaged } \\
\text { schools }\end{array}$ & $\begin{array}{c}\text { Difference } \\
(\text { Adv-Disadv) }\end{array}$ & $\begin{array}{c}\text { Average } \\
\text { efficiency } \\
\text { (all schools) }\end{array}$ \\
\hline 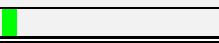 & (a) & (b) & (c) & $(d)=[(c-a) / a]$ & (e) \\
\hline $\begin{array}{l}\text { United Arab } \\
\text { Emirates }\end{array}$ & 0.620 & 0.687 & 0.761 & $22.7 \%$ & 0.691 \\
\hline Argentina & 0.562 & 0.631 & 0.739 & $31.5 \%$ & 0.637 \\
\hline Bulgaria & 0.582 & 0.657 & 0.845 & $45.2 \%$ & 0.687 \\
\hline Brazil & 0.658 & 0.668 & 0.730 & $11.0 \%$ & 0.681 \\
\hline Chile & 0.628 & 0.717 & 0.810 & $29.0 \%$ & 0.719 \\
\hline Colombia & 0.632 & 0.684 & 0.748 & $18.3 \%$ & 0.688 \\
\hline Costa Rica & 0.694 & 0.707 & 0.773 & $11.4 \%$ & 0.722 \\
\hline Greece & 0.618 & 0.734 & 0.800 & $29.5 \%$ & 0.718 \\
\hline Croatia & 0.690 & 0.733 & 0.863 & $25.2 \%$ & 0.754 \\
\hline Hungary & 0.615 & 0.741 & 0.857 & $39.4 \%$ & 0.739 \\
\hline Indonesia & 0.667 & 0.660 & 0.693 & $3.9 \%$ & 0.670 \\
\hline Jordan & 0.613 & 0.618 & 0.663 & $8.1 \%$ & 0.629 \\
\hline Kazakhstan & 0.622 & 0.632 & 0.707 & $13.5 \%$ & 0.649 \\
\hline Lithuania & 0.654 & 0.716 & 0.807 & $23.3 \%$ & 0.725 \\
\hline Latvia & 0.683 & 0.741 & 0.826 & $21.0 \%$ & 0.748 \\
\hline Mexico & 0.678 & 0.709 & 0.758 & $11.8 \%$ & 0.713 \\
\hline Montenegro & 0.546 & 0.646 & 0.729 & $33.7 \%$ & 0.642 \\
\hline Malaysia & 0.626 & 0.639 & 0.729 & $16.5 \%$ & 0.658 \\
\hline Peru & 0.543 & 0.605 & 0.716 & $31.9 \%$ & 0.618 \\
\hline Qatar & 0.524 & 0.604 & 0.699 & $33.4 \%$ & 0.609 \\
\hline Romania & 0.637 & 0.686 & 0.812 & $27.6 \%$ & 0.705 \\
\hline $\begin{array}{l}\text { Russian } \\
\text { Federation }\end{array}$ & 0.689 & 0.731 & 0.815 & $18.2 \%$ & 0.740 \\
\hline Serbia & 0.627 & 0.683 & 0.804 & $28.3 \div$ & 0.696 \\
\hline Thailand & 0.703 & 0.704 & 0.818 & $16.5 \%$ & 0.732 \\
\hline Tunisia & 0.605 & 0.658 & 0.745 & $23.1 \%$ & 0.664 \\
\hline Turkey & 0.729 & 0.773 & 0.860 & $17.9 \%$ & 0.785 \\
\hline Uruguay & 0.567 & 0.655 & 0.756 & $33.4 \%$ & 0.660 \\
\hline Viet Nam & 0.777 & 0.840 & 0.877 & $12.9 \%$ & 0.834 \\
\hline Total & 0.645 & 0.690 & 0.770 & $19.3 \%$ & 0.699 \\
\hline
\end{tabular}

Notes.

Efficiency score obtained with the international frontier as benchmark. (a) "disadvantaged" schools are those in which the average students' ESCS is below the $25^{\text {th }}$ percentile of the within-country ESCS distribution; (b) "advantaged" schools are defined so when their students" average ESCS is above the $75^{\text {th }}$ percentile of the withincountry ESCS distribution (residually, "average" schools in (c) are those whose students' average ESCS is between $25^{\text {th }}$ and $75^{\text {th }}$ percentiles of the within-country ESCS distribution).

(e) The efficiency scores are obtained through the baseline model that considers all the schools together (international frontier) 
Table 2. The characteristics of most and least efficient schools: descriptive statistics, by country

Panel A. Schools in the $10 \%$ of most efficient schools, internationally

\begin{tabular}{|c|c|c|c|c|c|c|c|c|c|}
\hline Country & $\begin{array}{c}n \\
\text { efficie } \\
\text { nt* }\end{array}$ & ESCS & $\begin{array}{c}\text { StRati } \\
\circ\end{array}$ & $\underset{n}{\text { Computer }}$ & $\underset{\mathrm{h}}{\mathrm{pv} 1 \mathrm{mat}}$ & $\begin{array}{c}\text { pv1rea } \\
\text { d }\end{array}$ & $\begin{array}{l}\mathrm{n} \text { total } \\
\text { (country } \\
1\end{array}$ & $\begin{array}{c}\text { oefficien } \\
t \\
\text { (country) }\end{array}$ & $\begin{array}{c}\text { officien } \\
t \\
\text { (frontier } \\
\text { ) }\end{array}$ \\
\hline & (a) & (b) & (c) & (d) & (e) & $(\mathrm{f})$ & (g) & (h) $=a / g$ & (i) $=a / 875$ \\
\hline $\begin{array}{l}\text { United Arab } \\
\text { Emirates }\end{array}$ & 49 & 0.735 & 0.138 & 0.863 & 535.58 & 546.12 & 402 & $12.2 \%$ & $5.6 \%$ \\
\hline Argentina & 3 & 0.463 & 0.162 & 0.521 & 520.34 & 526.30 & 172 & $1.7 \%$ & $0.3 \%$ \\
\hline Bulgaria & 34 & 0.356 & 0.069 & 0.343 & 525.71 & 547.11 & 183 & $18.6 \%$ & $3.9 \%$ \\
\hline Brazil & 48 & -0.493 & 0.039 & 0.251 & 466.74 & 483.79 & 681 & $7.0 \%$ & $5.5 \%$ \\
\hline Chile & 31 & 0.960 & 0.098 & 0.662 & 529.92 & 540.48 & 199 & $15.6 \%$ & $3.5 \%$ \\
\hline Colombia & 14 & 0.161 & 0.048 & 0.624 & 493.75 & 520.02 & 321 & $4.4 \%$ & $1.6 \%$ \\
\hline Costa Rica & 18 & -0.233 & 0.097 & 0.581 & 468.44 & 506.18 & 149 & $12.1 \%$ & $2.1 \%$ \\
\hline Greece & 22 & 0.374 & 0.119 & 0.189 & 504.49 & 544.06 & 166 & $13.3 \%$ & $2.5 \%$ \\
\hline Croatia & 40 & 0.156 & 0.073 & 0.249 & 541.52 & 560.84 & 157 & $25.5 \%$ & $4.6 \%$ \\
\hline Hungary & 54 & 0.311 & 0.083 & 0.596 & 555.13 & 566.06 & 196 & $27.6 \%$ & $6.2 \%$ \\
\hline Indonesia & 10 & -1.618 & 0.061 & 0.207 & 454.98 & 483.81 & 194 & $5.2 \%$ & $1.1 \%$ \\
\hline Jordan & 2 & 0.291 & 0.105 & 0.505 & 513.80 & 508.96 & 205 & $1.0 \%$ & $0.2 \%$ \\
\hline Kazakhstan & 4 & -0.412 & 0.159 & 0.247 & 534.45 & 461.91 & 212 & $1.9 \%$ & $0.5 \%$ \\
\hline Lithuania & 26 & 0.369 & 0.078 & 0.500 & 553.23 & 556.72 & 200 & $13.0 \%$ & $3.0 \%$ \\
\hline Latvia & 33 & 0.216 & 0.133 & 0.835 & 552.47 & 551.08 & 200 & $16.5 \%$ & $3.8 \%$ \\
\hline Mexico & 170 & -0.843 & 0.036 & 0.207 & 463.13 & 480.77 & 1240 & $13.7 \%$ & $19.4 \%$ \\
\hline Montenegro & 1 & 0.725 & 0.050 & 0.087 & 527.58 & 531.77 & 50 & $2.0 \%$ & $0.1 \%$ \\
\hline Malaysia & 4 & 0.120 & 0.125 & 0.301 & 513.74 & 476.44 & 163 & $2.5 \%$ & $0.5 \%$ \\
\hline Peru & 3 & -0.459 & 0.061 & 0.442 & 464.05 & 506.16 & 212 & $1.4 \%$ & $0.3 \%$ \\
\hline Qatar & 8 & 0.937 & 0.080 & 1.198 & 516.03 & 539.16 & 136 & $5.9 \%$ & $0.9 \%$ \\
\hline Romania & 25 & 0.362 & 0.072 & 0.526 & 543.71 & 542.12 & 177 & $14.1 \%$ & $2.9 \div$ \\
\hline Russian Federation & 36 & 0.271 & 0.074 & 0.678 & 536.46 & 540.67 & 212 & $17.0 \%$ & $4.1 \%$ \\
\hline Serbia & 15 & 0.353 & 0.075 & 0.134 & 544.83 & 543.39 & 129 & $11.6 \%$ & $1.7 \%$ \\
\hline Thailand & 41 & -0.235 & 0.066 & 0.554 & 551.80 & 534.78 & 239 & $17.2 \%$ & $4.7 \%$ \\
\hline Tunisia & 6 & 0.030 & 0.120 & 0.757 & 512.01 & 515.93 & 129 & $4.7 \%$ & $0.7 \%$ \\
\hline Turkey & 59 & -1.212 & 0.078 & 0.115 & 507.02 & 527.82 & 161 & $36.6 \%$ & $6.7 \%$ \\
\hline Uruguay & 10 & 0.442 & 0.079 & 0.331 & 510.07 & 526.58 & 175 & $5.7 \%$ & $1.1 \%$ \\
\hline Viet Nam & 109 & -1.817 & 0.055 & 0.150 & 528.84 & 527.14 & 158 & $69.0 \%$ & $12.5 \%$ \\
\hline Total & 875 & -0.345 & 0.072 & 0.387 & 513.36 & 524.23 & 6,818 & $12.8 \%$ & $100.0 \%$ \\
\hline
\end{tabular}


Panel B. Schools in the $10 \%$ of most inefficient schools, internationally

\begin{tabular}{|c|c|c|c|c|c|c|c|c|c|}
\hline Country & $\begin{array}{c}n \\
\text { ineffici } \\
\text { ent* }\end{array}$ & ESCS & $\begin{array}{c}\text { StRati } \\
\circ\end{array}$ & $\begin{array}{c}\text { Comput } \\
\mathrm{n}\end{array}$ & $\underset{\mathrm{h}}{\mathrm{pv} 1 \mathrm{mat}}$ & $\begin{array}{c}\text { pv1rea } \\
\text { d }\end{array}$ & $\begin{array}{l}\text { n total } \\
\text { (country } \\
\text { ) }\end{array}$ & $\begin{array}{c}\text { oefficien } \\
t \\
\text { (country) }\end{array}$ & $\begin{array}{c}\text { oefficien } \\
t \\
\text { (frontier } \\
\text { ) }\end{array}$ \\
\hline & (a) & (b) & (c) & (d) & (e) & (f) & (g) & (h) $=a / g$ & (i) $=a / 875$ \\
\hline $\begin{array}{l}\text { United Arab } \\
\text { Emirates }\end{array}$ & 69 & -0.106 & 0.111 & 0.395 & 343.86 & 323.59 & 402 & $17.2 \%$ & $8.3 \%$ \\
\hline Argentina & 54 & -1.188 & 0.166 & 0.577 & 332.11 & 322.06 & 172 & $31.4 \%$ & $6.5 \%$ \\
\hline Bulgaria & 46 & -0.949 & 0.121 & 0.625 & 348.21 & 308.93 & 183 & $25.1 \%$ & $5.5 \%$ \\
\hline Brazil & 84 & -1.713 & 0.050 & 0.063 & 306.39 & 305.12 & 681 & $12.3 \%$ & $10.1 \%$ \\
\hline Chile & 15 & -1.549 & 0.071 & 1.225 & 319.12 & 323.67 & 199 & $7.5 \%$ & $1.8 \%$ \\
\hline Colombia & 31 & -1.864 & 0.067 & 0.483 & 313.93 & 316.67 & 321 & $9.7 \%$ & $3.7 \%$ \\
\hline Costa Rica & 4 & -1.813 & 0.062 & 0.133 & 310.77 & 326.72 & 149 & $2.7 \%$ & $0.5 \%$ \\
\hline Greece & 22 & -0.638 & 0.158 & 0.363 & 340.27 & 331.55 & 166 & $13.3 \%$ & $2.7 \%$ \\
\hline Croatia & 6 & -0.880 & 0.115 & 0.234 & 374.16 & 352.83 & 157 & $3.8 \%$ & $0.7 \%$ \\
\hline Hungary & 18 & -1.167 & 0.095 & 0.729 & 344.31 & 336.31 & 196 & $9.2 \%$ & $2.2 \%$ \\
\hline Indonesia & 27 & -1.894 & 0.100 & 0.137 & 311.51 & 312.42 & 194 & $13.9 \%$ & $3.3 \%$ \\
\hline Jordan & 63 & -0.634 & 0.096 & 0.373 & 337.59 & 318.31 & 205 & $30.7 \%$ & $7.6 \%$ \\
\hline Kazakhstan & 41 & -0.669 & 0.142 & 0.695 & 378.60 & 334.71 & 212 & $19.3 \%$ & $4.9 \%$ \\
\hline Lithuania & 8 & -0.716 & 0.261 & 1.625 & 357.57 & 332.74 & 200 & $4.0 \%$ & $1.0 \%$ \\
\hline Latvia & 2 & -0.961 & 0.116 & 1.088 & 385.30 & 368.17 & 200 & $1.0 \%$ & $0.2 \%$ \\
\hline Mexico & 73 & -2.018 & 0.102 & 0.355 & 323.95 & 305.76 & 1240 & $5.9 \%$ & $8.8 \%$ \\
\hline Montenegro & 12 & -0.685 & 0.117 & 0.266 & 344.41 & 334.95 & 50 & $24.0 \%$ & $1.4 \%$ \\
\hline Malaysia & 16 & -1.012 & 0.080 & 0.278 & 367.12 & 339.65 & 163 & $9.8 \%$ & $1.9 \%$ \\
\hline Peru & 76 & -1.990 & 0.098 & 0.383 & 302.10 & 303.37 & 212 & $35.8 \%$ & $9.2 \%$ \\
\hline Qatar & 57 & 0.138 & 0.112 & 0.606 & 320.76 & 309.26 & 136 & $41.9 \%$ & $6.9 \%$ \\
\hline Romania & 16 & -1.281 & 0.074 & 0.476 & 359.27 & 332.98 & 177 & $9.0 \%$ & $1.9 \%$ \\
\hline Russian Federation & 3 & -0.346 & 0.160 & 0.765 & 380.20 & 357.20 & 212 & $1.4 \%$ & $0.4 \%$ \\
\hline Serbia & 12 & -0.606 & 0.110 & 0.232 & 364.48 & 348.14 & 129 & $9.3 \%$ & $1.4 \%$ \\
\hline Thailand & 7 & -1.785 & 0.066 & 0.612 & 334.30 & 320.55 & 239 & $2.9 \%$ & $0.8 \%$ \\
\hline Tunisia & 29 & -1.668 & 0.086 & 0.507 & 324.52 & 313.70 & 129 & $22.5 \%$ & $3.5 \%$ \\
\hline Turkey & 2 & -2.120 & 0.067 & 0.379 & 344.15 & 330.65 & 161 & $1.2 \%$ & $0.2 \%$ \\
\hline Uruguay & 36 & -1.587 & 0.100 & 0.741 & 331.45 & 318.52 & 175 & $20.6 \%$ & $4.3 \%$ \\
\hline Viet Nam & 1 & -2.478 & 0.066 & 1.143 & 346.65 & 338.82 & 158 & $0.6 \%$ & $0.1 \%$ \\
\hline Total & 830 & -1.184 & 0.104 & 0.454 & 331.10 & 317.42 & 6,818 & $12.2 \%$ & $100.0 \%$ \\
\hline
\end{tabular}

Notes. The most efficient schools are those which efficiency score is $>90^{\text {th }}$ percentile, while the least efficient ones have an efficiency score $<10^{\text {th }}$ percentile. 
Table 3. Factors associated with efficiency: a second-stage analysis through the Simar \& Wilson (2007) procedure

\begin{tabular}{|c|c|c|c|c|c|c|}
\hline Variable & Coefficient & SE & $\mathrm{z}$ & $\mathrm{P}>\mathrm{z}$ & $\begin{array}{l}{[95 \%} \\
\text { Conf. }\end{array}$ & Interval] \\
\hline \multicolumn{7}{|l|}{ Students' characteristics } \\
\hline female & 0.0506 & 0.011 & 4.64 & 0.000 & 0.030 & 0.071 \\
\hline hwork_h & 0.0047 & 0.001 & 4.82 & 0.000 & 0.003 & 0.007 \\
\hline repeater & -0.0873 & 0.012 & -7.07 & 0.000 & -0.111 & -0.062 \\
\hline st_truancy & -0.0765 & 0.013 & -5.79 & 0.000 & -0.104 & -0.052 \\
\hline ESCSsd & -0.0521 & 0.009 & -5.61 & 0.000 & -0.071 & -0.034 \\
\hline pv1mathsd & \multirow{2}{*}{$\begin{array}{l}0.0004 \\
0.0346\end{array}$} & 0.000 & 2.48 & 0.013 & 0.000 & 0.001 \\
\hline pm_important & & 0.015 & 2.23 & 0.026 & 0.005 & 0.064 \\
\hline \multicolumn{7}{|l|}{ School's general features } \\
\hline isced2 & -0.0209 & 0.009 & -2.36 & 0.018 & -0.039 & -0.004 \\
\hline orgen & 0.0204 & 0.009 & 2.34 & 0.019 & 0.003 & 0.037 \\
\hline private & \multirow{2}{*}{$\begin{array}{c}0.0164 \\
-0.0112\end{array}$} & 0.006 & 2.54 & 0.011 & 0.004 & 0.029 \\
\hline village & & 0.006 & -1.99 & 0.047 & -0.022 & 0.000 \\
\hline size10 & 0.0003 & 0.000 & 6.59 & 0.000 & 0.000 & 0.000 \\
\hline \multicolumn{7}{|l|}{ Resources } \\
\hline sc_matedu & \multirow{2}{*}{$\begin{array}{l}0.0054 \\
0.0001\end{array}$} & 0.002 & 2.64 & 0.008 & 0.002 & 0.010 \\
\hline mminutes & & 0.000 & 1.58 & 0.113 & 0.000 & 0.000 \\
\hline \multicolumn{7}{|l|}{ Teachers' characteristics } \\
\hline tc_part & 0.0025 & 0.002 & 1.16 & 0.248 & -0.002 & 0.007 \\
\hline t_clim & 0.0035 & 0.002 & 1.94 & 0.052 & 0.000 & 0.007 \\
\hline t_develop & 0.0001 & 0.000 & 1.47 & 0.143 & 0.000 & 0.000 \\
\hline \multicolumn{7}{|l|}{ Practices and processes } \\
\hline accountability_1 & 0.0049 & 0.004 & 1.10 & 0.273 & -0.003 & 0.014 \\
\hline extracur & 0.0032 & 0.002 & 1.52 & 0.128 & -0.001 & 0.007 \\
\hline competition & 0.0078 & 0.004 & 1.78 & 0.075 & -0.001 & 0.016 \\
\hline select_1 & 0.0053 & 0.005 & 1.16 & 0.246 & -0.004 & 0.014 \\
\hline Constant & 0.6803 & 0.021 & 31.96 & 0.000 & 0.638 & 0.724 \\
\hline /sigma & 0.0674 & 0.001 & 51.19 & 0.000 & 0.064 & 0.069 \\
\hline Country dummies & $\mathrm{Y}$ & 1 & I & t & 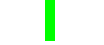 & T \\
\hline Program type dummies & $\mathrm{Y}$ & & & & & \\
\hline Number of observations & 6178 & & & & & \\
\hline
\end{tabular}

\section{Notes.}

First column: the estimation of the model has been conducted through the package SIMARWILSON.

The dependent variable is the bias-corrected, bootstrap efficiency score of each school, obtained through the baseline model (with the international benchmark as reference for the frontier of efficient schools). We use the algorithm \#1 proposed in Simar \& Wilson (2007). See section \$2.1 for a description of the variables' labels and their description. 
Table 4. Efficiency scores, by continent

\begin{tabular}{lcccc}
\hline Continent & mean & sd & $\min$ & $\max$ \\
\hline \hline Europe & 0.720 & 0.104 & 0.397 & 0.977 \\
Americas & 0.691 & 0.090 & 0.383 & 0.947 \\
Africa & 0.664 & 0.101 & 0.442 & 0.899 \\
Asia & 0.685 & 0.108 & 0.339 & 0.969 \\
Eurasia & 0.760 & 0.087 & 0.541 & 0.975 \\
\hline Total & 0.699 & 0.100 & 0.339 & 0.977 \\
\hline
\end{tabular}

Notes. Efficiency score obtained with the international frontier as benchmark. Africa has only one country (Tunisia). Eurasia is composed by Turkey and Russia. 
Figure 1. The distribution of efficiency scores, by country

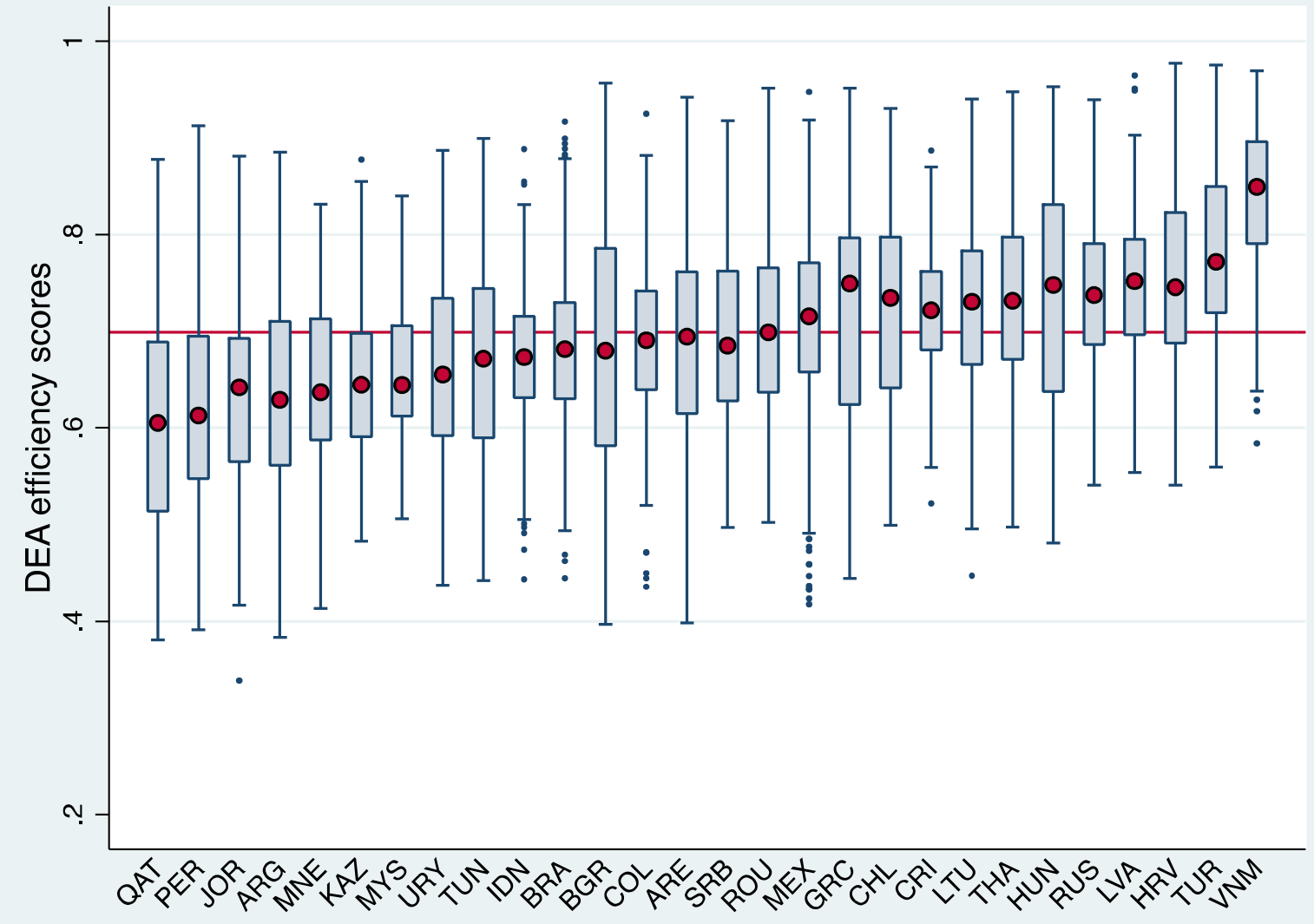

Notes. The boxes represent the $25^{\text {th }}$ and $75^{\text {th }}$ percentiles of efficiency scores' distribution, while the whiskers are the upper and lower "adjacent values", respectively, and the points are outliners. The red circle indicates the median of the distribution. Efficiency scores are obtained through the baseline model where an international benchmark is considered for building the frontier of efficient schools. 
Figure 2. Efficiency scores and performance (test scores), by country

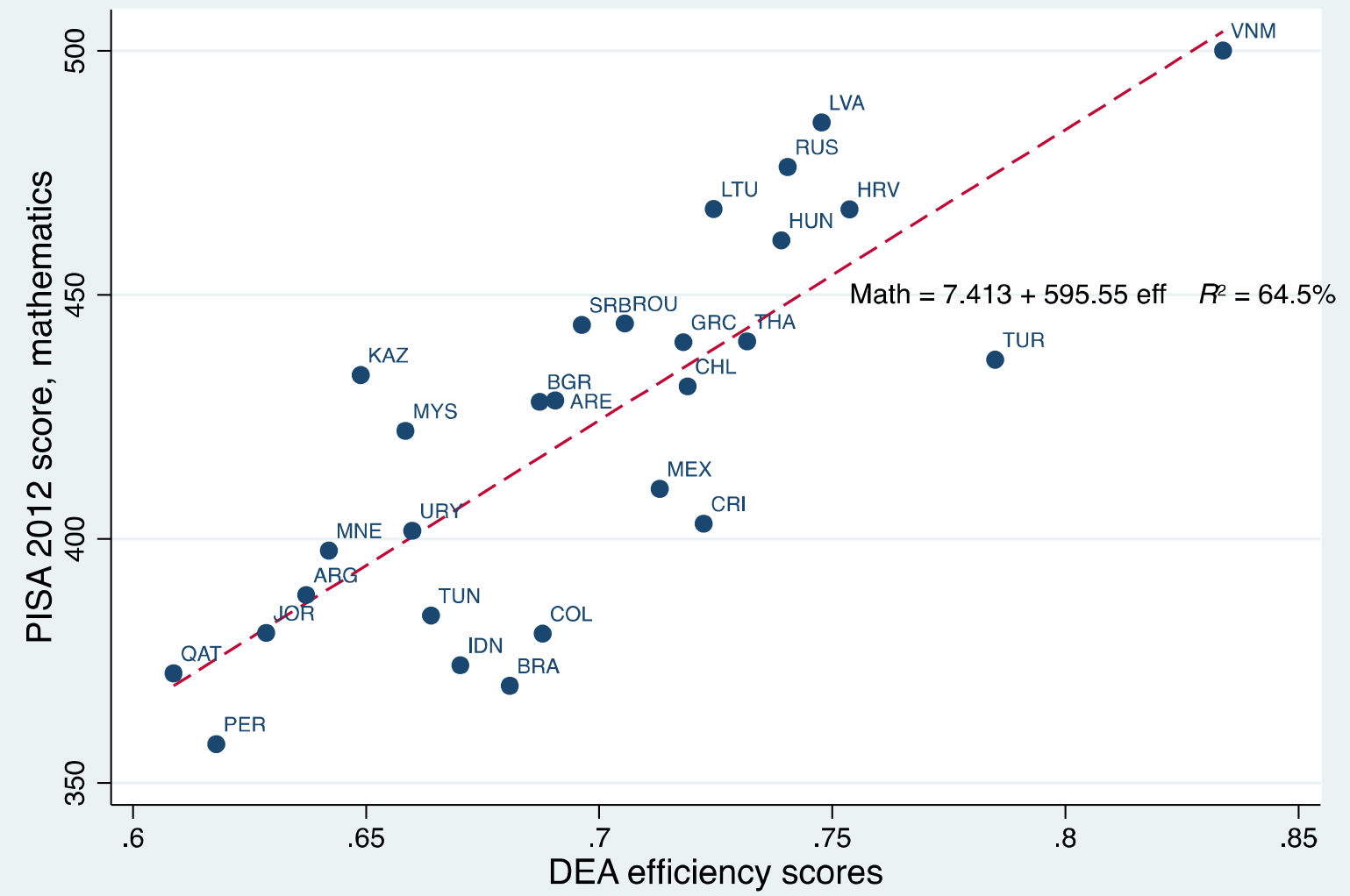

Notes. PISA 2012 scores in mathematics are countries' averages of school average scores, and refer to Plausible Value 1. Efficiency scores are obtained through the baseline model where an international benchmark is considered for building the frontier of efficient schools. 
Figure 3. The distribution of efficiency scores, by average students' advantaged/disadvantaged status

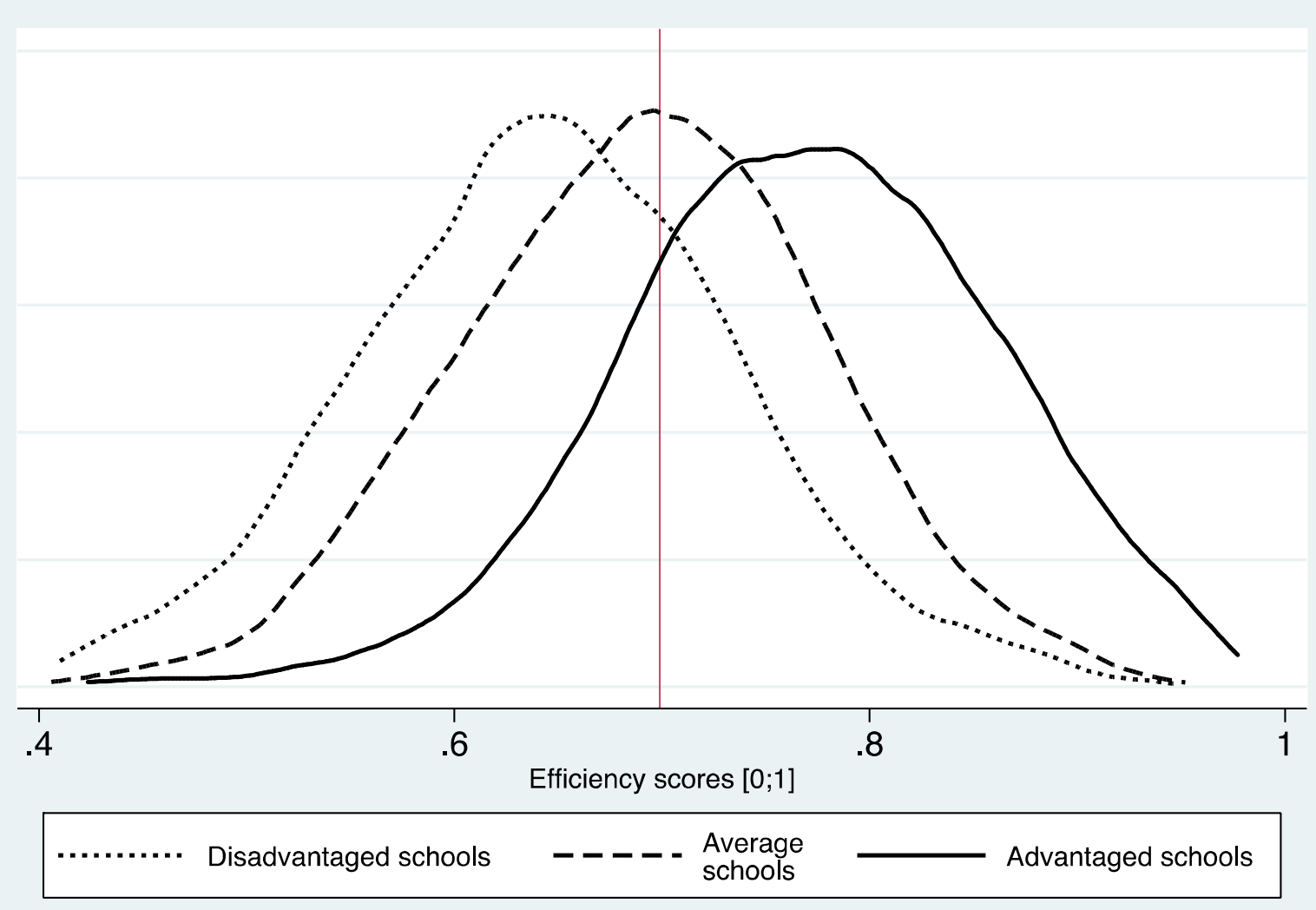

Density on the vertical axis

\section{Notes.}

A school is defined "advantaged" if the school-average students' ESCS is above the $25^{\text {th }}$ percentile of the withincountry ESCS distribution; conversely, it is defined "disadvantaged" if its ESCS is below the $25^{\text {th }}$ percentile of the within-country ESCS distribution. The efficiency scores are estimated when considering the "international benchmark" (all the schools are in the same empirical analysis, together). 
Figure 4. The distribution of efficiency scores, by average students' advantaged/disadvantaged status and by country

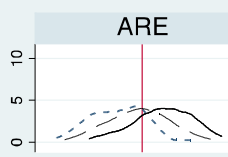

CRI
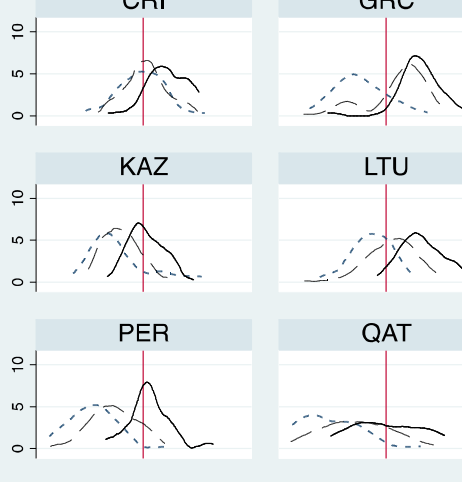

GRC

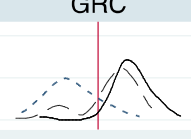

LTU
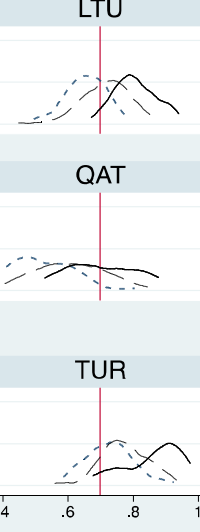

On the horizontal axis: efficiency scores

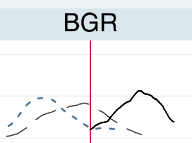

HRV

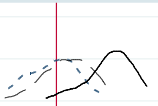

LVA

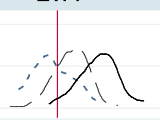

ROU

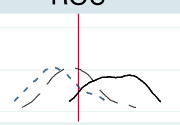

\begin{abstract}
URY
\end{abstract}

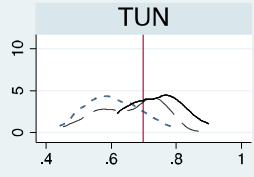

. Disadvantaged schools

---- Average schools

Advantaged schools

Vertical line: average efficiency (international frontier). Density on the vertical axis

Notes.

A school is defined "advantaged" if the school-average students' ESCS is above the $25^{\text {th }}$ percentile of the withincountry ESCS distribution; conversely, it is defined "disadvantaged" if its ESCS is below the $25^{\text {th }}$ percentile of the within-country ESCS distribution. The efficiency scores are estimated when considering the "international benchmark" (all the schools are in the same empirical analysis, together). 
Figure 5. Efficiency scores, by proportion of student whose proficiency level is below level 1

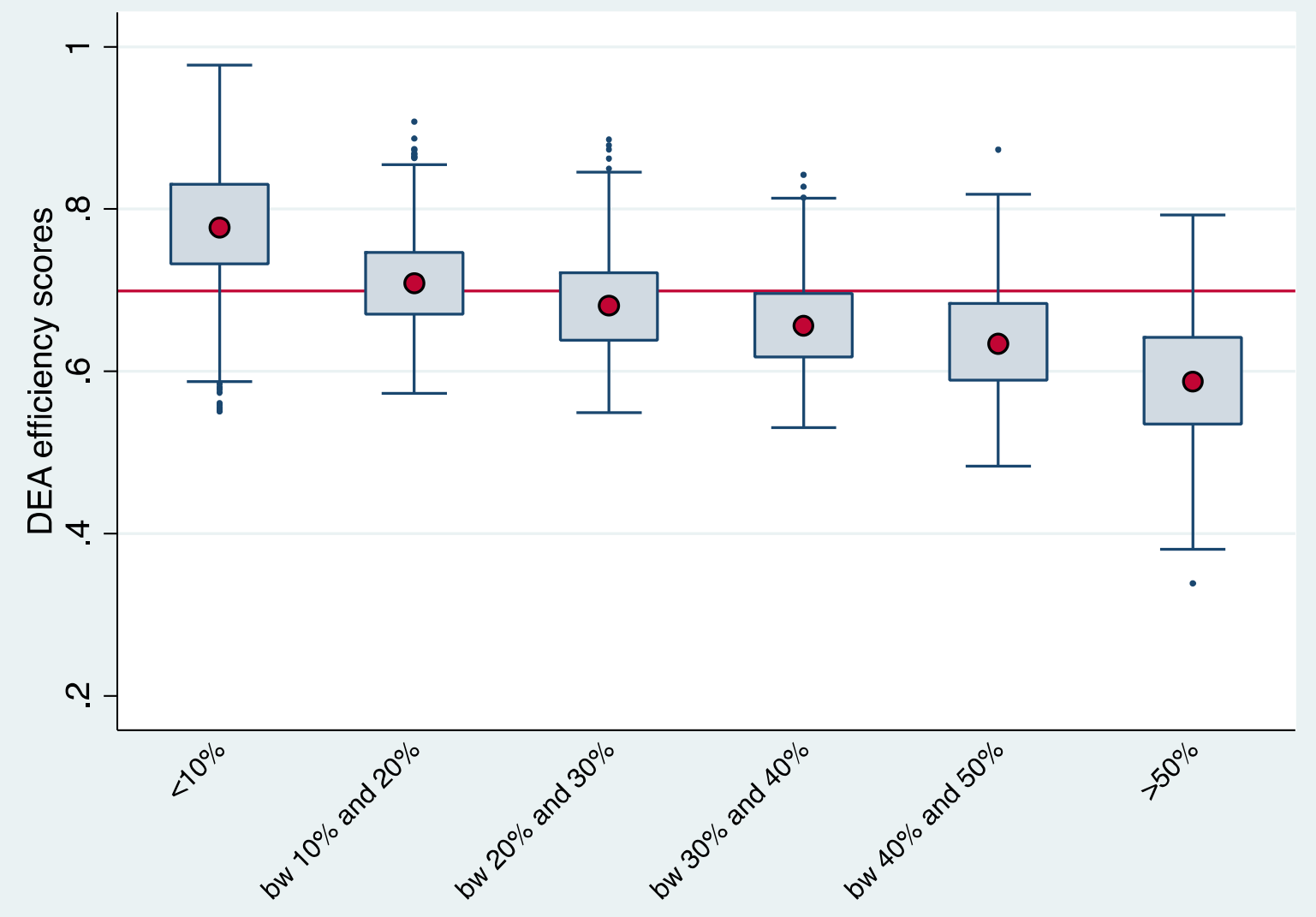

Notes: observations for which pv_belowprof1 is $=0$ have been excluded. Efficiency scores are those determined in the baseline model, where the international frontier is considered as a benchmark. 
Figure 6. Efficiency scores' distribution, by continent
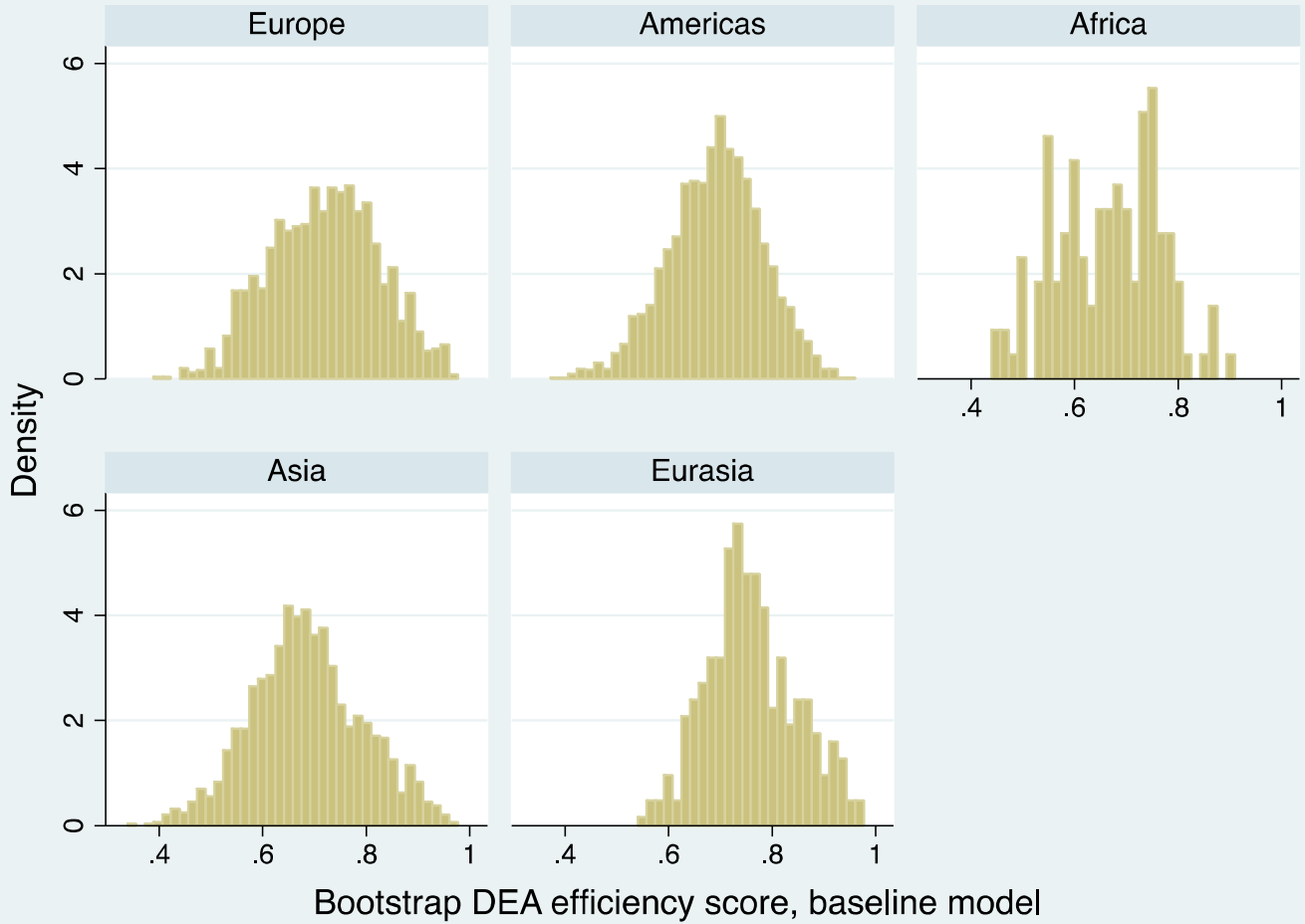

Notes. Efficiency score obtained with the international frontier as benchmark. Africa has only one country (Tunisia). Eurasia is composed by Turkey and Russia. 